Check for updates

Cite this: RSC Adv., 2017, 7, 33185

Received 12th April 2017

Accepted 26th June 2017

DOI: $10.1039 / \mathrm{c} 7 \mathrm{ra0} 4162 \mathrm{~d}$

rsc.li/rsc-advances

\section{Metal-catalyst-free growth of graphene on insulating substrates by ammonia-assisted microwave plasma-enhanced chemical vapor deposition}

\begin{abstract}
Shan Zheng, Guofang Zhong, (D) * Xingyi Wu, (D) Lorenzo D'Arsiè and John Robertson
We study the metal-catalyst-free growth of uniform and continuous graphene films on different insulating substrates by microwave plasma-enhanced chemical vapor deposition (PECVD) with a gas mixture of $\mathrm{C}_{2} \mathrm{H}_{2}$, $\mathrm{NH}_{3}$, and $\mathrm{H}_{2}$ at a relatively low temperature of $700-750{ }^{\circ} \mathrm{C}$. Compared to growth using only $\mathrm{C}_{2} \mathrm{H}_{2}$ and $\mathrm{H}_{2}$, the use of $\mathrm{NH}_{3}$ during synthesis is found to be beneficial, in transforming vertical graphene nano-walls into a layer-by-layer film, reducing the density of defects, and improving the graphene quality. The effect of different insulating substrates (including $\mathrm{Al}_{2} \mathrm{O}_{3}$ and $\mathrm{SiO}_{2}$ ) on the growth of graphene was studied under different growth temperatures, implying that the growth-temperature window and catalytic effect vary among insulators. The low activation energy barrier of $\mathrm{Al}_{2} \mathrm{O}_{3}$ proves it to be a more suitable substrate for the metal-catalyst-free growth of graphene at low temperature. These directly grown graphene films on insulators can be conveniently integrated into various electronic and optoelectronic applications avoiding any post-growth transfer processes.
\end{abstract}

\section{Introduction}

Graphene is a two-dimensional, single-layer sheet of $\mathrm{sp}^{2}$ bonded carbon atoms packed into a honeycomb lattice. It has been regarded as one of the most attractive candidates for future electrical and optical applications owing to its excellent properties such as high carrier mobility, optical transparency, mechanical flexibility, and high thermal conductivity. ${ }^{\mathbf{1 , 2}}$ To fully realize its potential in real-world devices, metal-catalyst chemical vapor deposition (CVD) has been widely used in the largescale, high-quality and cost-effective synthesis of graphene. However, this method has significant limitations in that the growth is normally carried out at $\sim 1000{ }^{\circ} \mathrm{C},{ }^{3-8}$ on a metal catalyst and requires a post-growth transfer process from metal onto an insulating substrate to make the device. The difficult transfer process usually results in polymer or metal residues, and wrinkling or breakage of graphene..$^{9-11}$ Therefore, it would be a great advantage to develop a direct, metal-free growth method of graphene onto insulating substrates at low temperature.

Unfortunately, insulating substrates generally display weak catalytic nature. The principle role of the catalyst in graphene growth is to dehydrogenate the precursor species ${ }^{\mathbf{1 2}}$ and to chemisorb the hydrocarbon as a mobile surface species to cluster into the growing graphene grains. Some oxides such as $\mathrm{VO}_{x}$ and $\mathrm{Cr}_{2} \mathrm{O}_{3}$ can act as dehydrogenation catalysts. The

Department of Engineering, University of Cambridge, Cambridge CB2 1PZ, UK. E-mail: gz222@cam.ac.uk; Tel: +44 (0) 1223748317 stability of strongly bonded oxides such as $\mathrm{ZrO}_{2}$ or $\mathrm{HfO}_{2}$ against reduction by carbon and have been used to grow carbon nano structures. ${ }^{13-16}$ There is also the novel idea of using remote copper or iron based catalysts which are then volatilized after the graphene growth. ${ }^{17}$ Nevertheless, the direct growth of graphene onto insulating substrates has been frequently tried and tends to show degraded quality compared with those grown on metals. ${ }^{18}$ In order to overcome the large energy barrier for graphene nucleation without metal catalysts, ${ }^{19}$ even higher temperatures $\left(1065-1650{ }^{\circ} \mathrm{C}\right)$ are required by thermal CVD to obtain graphene to compete with the metal-catalyzed growth. ${ }^{20-24}$

To lower the growth temperature, it is useful to consider plasma-enhanced chemical vapor deposition (PECVD). ${ }^{25}$ The presence of energetic electrons, excited molecules/atoms, and free radicals generated in the plasma region can promote the decomposition of reactant gases, thus partly compensating for the weak catalytic nature of insulating substrates. ${ }^{26}$ Several PECVD studies have been reported on $\mathrm{SiO}_{2},{ }^{27-38}$ quartz, ${ }^{27,31,38}$ glass, ${ }^{34,39}$ and $\mathrm{Al}_{2} \mathrm{O}_{3}{ }^{28,38}$ to explore the synthesis of graphene without metal catalysts at low temperature. Successful enlargement of isolated grain sizes has been realized using twostep growth in PECVD process. ${ }^{27-30}$ However, extremely long growth times (over 9 hours) ${ }^{27}$ or high-temperature preannealing $\left(1000{ }^{\circ} \mathrm{C}\right)^{29}$ was still needed to obtain isolated grains, and high mobility values were only measured on single grain devices due to discontinuous films. ${ }^{28-30}$ Other groups tried to grow continuous graphene using PECVD. However, these 
films suffered from common problems such as many defects, less surface uniformity, ${ }^{31-39}$ and three-dimensional (3D) nanowall growth..$^{31,34,37,40}$ All these drawbacks have limited graphene from fulfilling its excellent electrical properties and developing its advantage of atomic thickness. Therefore, a continuous, uniform, and two-dimensional graphene film with a low defect density is desirable, which can enable graphene integrated with the modern silicon electronics as well as other two-dimensional materials like transition metal dichalcogenides.

When it comes to device fabrication, insulators serve as gates in field-effect transistors (FETs), which have a strong influence on fulfilling the properties of graphene. However, the weak catalysis of insulators makes the selection of more proper insulating substrates essential in the metal-catalyst-free growth of graphene. $\mathrm{SiO}_{2}$ might not be an ideal substrate for graphene FETs, because the high interface states density and impurityinduced trapped charges on $\mathrm{SiO}_{2}$ substrates could cause carrier scattering issues that limit the performance of devices. ${ }^{\mathbf{4 1}}$ Recent studies suggest that using high dielectric constant (highк) materials like $\mathrm{Al}_{2} \mathrm{O}_{3}$ as gate insulators would boost the performance of devices due to the reduction of Coulomb scattering in graphene owing to the dielectric screening effect. ${ }^{42}$ Therefore, the direct assembly of graphene on high- $\kappa$ dielectrics would be useful. Atomic layer deposition (ALD) is a typical technique to obtain high-quality, thickness-controlled, pinholefree high- $\kappa$ thin films, which could provide a smooth and continuous surface for the graphene growth. ${ }^{43}$ Furthermore, the graphene/high- $\kappa$ dielectric structure could be easily applied onto any semiconductor or substrate for functional device fabrications. However, the only attempt of metal-catalyst-free PECVD growth of graphene on atomic layer deposited $\mathrm{Al}_{2} \mathrm{O}_{3}$ substrates $^{38}$ faced all the common problems mentioned above such as a high density of defects and multi-layer structures, but factors that degraded the quality and the mechanism behind it are not very clear.

Here, we demonstrate the metal-catalyst-free growth of graphene on $\mathrm{SiO}_{2}$ and $\mathrm{Al}_{2} \mathrm{O}_{3}$ by PECVD to investigate the possible solutions to reduce the density of defects and 3D nano-walls. By decreasing the concentration of the carbon gas and especially introducing $\mathrm{NH}_{3}$ in the growth, continuous and uniform graphene film with a low density of defects and no 3D nano-walls can be synthesized in our microwave PECVD system, thus the quality of graphene has been improved. Moreover, the graphene films produced on $\mathrm{SiO}_{2}$ and $\mathrm{Al}_{2} \mathrm{O}_{3}$ under different growth temperatures have been compared, which can offer a better understanding of the weak catalytic effect of different insulating substrates on the graphene growth.

\section{Experimental}

The low-temperature growth of graphene on various insulators was carried out in a homemade microwave (2.45 GHz) PECVD system using reactant gases including $\mathrm{C}_{2} \mathrm{H}_{2}, \mathrm{NH}_{3}$, and $\mathrm{H}_{2}$, as schematically shown in Fig. 1a. Dielectric substrates were placed on a PBN/PG (Pyrolytic Boron Nitride/Pyrolytic Graphite) heater element enclosed in a metal cage with a honeycomb mesh shield, as shown in the zoom-in image (Fig. 1b). This configuration can protect the samples from the ion-induced damage of the plasma ball, while the energetic and reactive species could pass through the mesh shield and reach the substrates to synthesize graphene. First, insulating substrates were heated to $650-750{ }^{\circ} \mathrm{C}$ after pumping down the chamber to $1 \times 10^{-6}$ mbar. Second, $\mathrm{H}_{2}$ was introduced at a rate of $400 \mathrm{sccm}$ and a microwave plasma was ignited above the metal cage at a pressure of $15 \mathrm{mbar}$ and a power of $600 \mathrm{~W}$ for $10 \mathrm{~min}$. Third, $\mathrm{C}_{2} \mathrm{H}_{2}$, or $\mathrm{C}_{2} \mathrm{H}_{2}$ and $\mathrm{NH}_{3}$ were added to the $\mathrm{H}_{2}$ flow to start the graphene growth. The total gas flow rate was kept at $400 \mathrm{sccm}$ $\left(\mathrm{C}_{2} \mathrm{H}_{2}: 20-40 \mathrm{sccm}, \mathrm{NH}_{3}: 0-120 \mathrm{sccm}\right.$, and $\left.\mathrm{H}_{2}: 240-360 \mathrm{sccm}\right)$. Finally, after three-hour growth, samples were cooled down by switching off the $\mathrm{C}_{2} \mathrm{H}_{2}$ and $\mathrm{NH}_{3}$ flow, the plasma, and the heater power supply.

High- $\kappa$ dielectric $\mathrm{Al}_{2} \mathrm{O}_{3}$ was deposited on $\mathrm{SiO}_{2}(300 \mathrm{~nm}) / \mathrm{p}-\mathrm{Si}$ wafer via ALD. Before the ALD process, all the wafers were cleaned by sonication in acetone, isopropyl alcohol, and deionized water, and then dried with $\mathrm{N}_{2}$. The cleaned wafers were placed in the chamber of Savannah S200 ALD reactor at the temperature of $200{ }^{\circ} \mathrm{C}$ with $\mathrm{N}_{2}$ introduced as both carrier gas and purge gas. $\mathrm{H}_{2} \mathrm{O}$ was used as the oxidant precursor, and trimethylaluminium (TMA) was the metal precursor for the deposition of $\mathrm{Al}_{2} \mathrm{O}_{3}$ dielectric surface. By changing the number of growth cycles, high- $\kappa$ thin film was obtained with thicknesses of $3 \mathrm{~nm}$ measured by ellipsometry. Besides $\mathrm{Al}_{2} \mathrm{O}_{3}, \mathrm{SiO}_{2}(300$ $\mathrm{nm}$ )/p-Si substrates were used as the control group in the graphene growth. Other insulating substrates were also tested in our experiments to investigate the effect of insulating substrates on the graphene growth, including sapphire, quartz, $\mathrm{MnO}_{2}$ spin coated on $\mathrm{SiO}_{2}$ substrates, $\mathrm{HfO}_{2}$ and $\mathrm{TiO}_{2}$ deposited on $\mathrm{SiO}_{2}$ substrates via ALD.

Several characterization techniques were used to investigate the quality and properties of the synthesized graphene. The surface morphology was observed by scanning electron microscopy (SEM, Carl Zeiss SIGMA, $1 \mathrm{kV}$ ), atomic force microscopy (AFM, Agilent 5500) and optical microscopy (Nikon ECLIPSE LV150N). The thicknesses of insulators were measured by ellipsometer (Gaertner L117). Raman spectroscopy (Renishaw InVia spectrometer, $457 \mathrm{~nm}$ excitation) was used to measure the crystallinity of graphene. Electrical properties were measured by a standard four-probe method (Keithley 4200-SCS Semiconductor Characterization System) at room temperature.

\section{Results and discussion}

We first tried to grow graphene by microwave PECVD using $\mathrm{H}_{2}$ and $\mathrm{C}_{2} \mathrm{H}_{2}$. It is found that $3 \mathrm{D}$ graphene commonly appears on both $\mathrm{SiO}_{2}$ and $\mathrm{Al}_{2} \mathrm{O}_{3}$ substrates at high $\mathrm{C}_{2} \mathrm{H}_{2}$ volume concentrations. However by decreasing the concentration of $\mathrm{C}_{2} \mathrm{H}_{2}$ from $10 \%$ to $5 \%$, 3D nano-walls can be greatly reduced on both substrates as shown in the left column (the blue area) in Fig. 2. PECVD assisted growth of graphene can be regarded as the competing result of graphene nucleation and growth due to the saturation of hydrocarbon precursors and the etching of carbon by atomic hydrogen. The abundant carbon source results in repeated nucleation and vertical growth under an insufficient $\mathrm{H}_{2}$ 
(a)

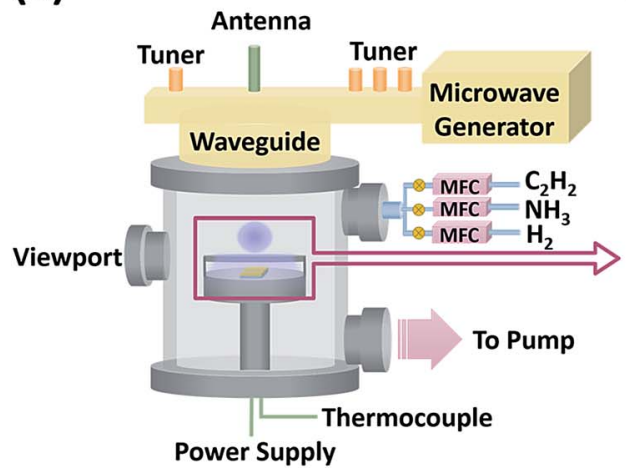

(b)

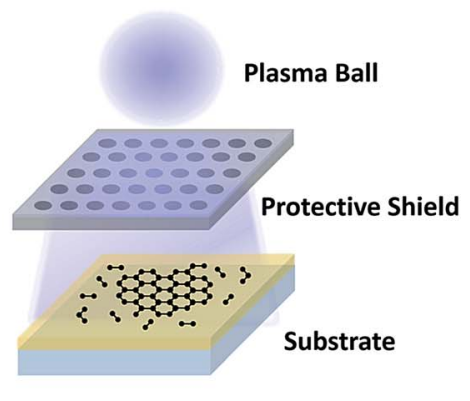

Fig. 1 Schematic illustrations of (a) the homemade microwave plasma-enhanced chemical vapor deposition system and (b) the zoom-in image of the graphene growth process.

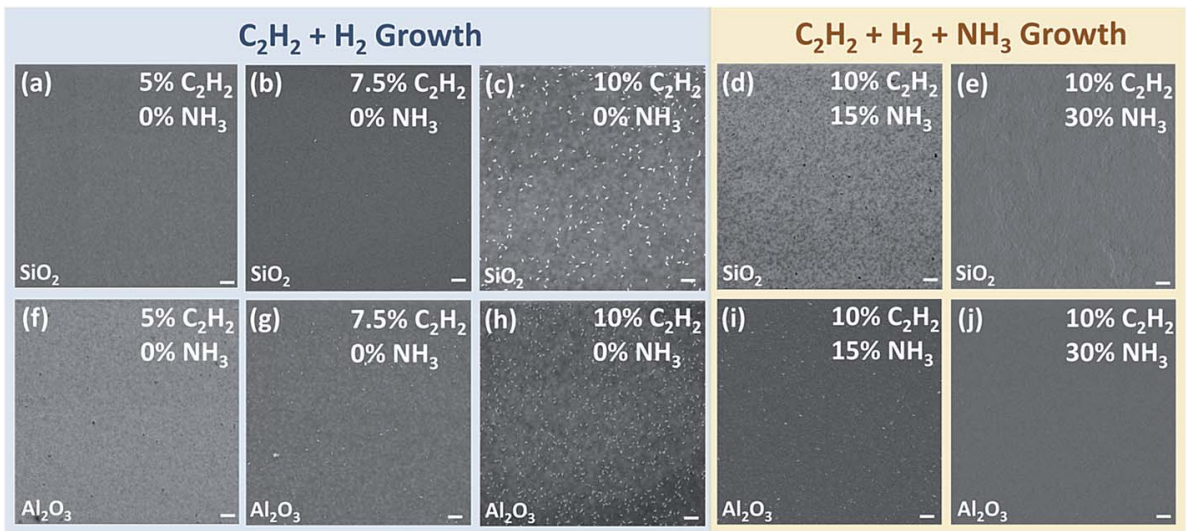

Fig. 2 SEM images of graphene grown directly on $\mathrm{SiO}_{2}(a-e)$ and $\mathrm{Al}_{2} \mathrm{O}_{3}(\mathrm{f}-\mathrm{j})$ at $750{ }^{\circ} \mathrm{C}$ for 3 hours by microwave $\mathrm{PECVD}$ using $\mathrm{C}_{2} \mathrm{H}_{2}+\mathrm{H}_{2}($ left column) and $\mathrm{C}_{2} \mathrm{H}_{2}+\mathrm{H}_{2}+\mathrm{NH}_{3}$ (right column), respectively. The $\mathrm{C}_{2} \mathrm{H}_{2}$ and $\mathrm{NH}_{3}$ concentrations are given in the images. The scale bars are 200 nm.

situation, which can be improved by reducing the concentration of carbon source to avoid excess carbon or increase the concentration of $\mathrm{H}_{2}$ to gain a strong etching effect. ${ }^{29,44,45}$ Compared with $\mathrm{H}_{2}$ plasma, $\mathrm{NH}_{3}$ plasma has been proved a more effective etching gas in generating atomic hydrogen species. ${ }^{28,46-48}$ To investigate the effect of $\mathrm{NH}_{3}$ on the growth of graphene, we intentionally keep the $\mathrm{C}_{2} \mathrm{H}_{2}$ concentration at a high level of $10 \%$, which will lead to $3 \mathrm{D}$ nano-wall growth of graphene (Fig. 2c and h) using $\mathrm{C}_{2} \mathrm{H}_{2} / \mathrm{H}_{2}$ plasma. With increasing $\mathrm{NH}_{3}$ concentration from 0 to $30 \%$, the surface morphology varies on both $\mathrm{SiO}_{2}$ and $\mathrm{Al}_{2} \mathrm{O}_{3}$ substrates, as shown in the right column (the yellow area) in Fig. 2. By replacing $40 \mathrm{sccm} \mathrm{H}_{2}$ with the same amount of $\mathrm{NH}_{3}\left(15 \% \mathrm{NH}_{3}\right)$, 3D nano-walls are reduced on both insulating substrates (Fig. $2 \mathrm{~d}$ and i). By increasing the $\mathrm{NH}_{3}$ concentration to $30 \%$, layer-by-layer structures are obtained on both insulating substrates (Fig. 2e and j). For the $\mathrm{SiO}_{2}$ substrate, the growth mode is in a layer-by-layer manner and the whole substrate is covered by graphene flakes. For the $\mathrm{Al}_{2} \mathrm{O}_{3}$ substrate, a continuous and uniform graphene sheet is directly synthesized on the substrate.

It has been also found that further increasing of $\mathrm{NH}_{3}$ will lead to the growth of discontinuous graphene. Wei et al. studied the growth of graphene by PECVD using only $\mathrm{NH}_{3}$ and a carbon source such as $\mathrm{C}_{2} \mathrm{H}_{2}, \mathrm{CH}_{4}$ or $\mathrm{C}_{2} \mathrm{H}_{4} \cdot{ }^{28}$ In their work, the growth temperature and the ratio of $\mathrm{NH}_{3}$ and hydrocarbon gas were systematically varied to find the optimal growth condition. High-quality graphene with low density of defects has been synthesized using this binary growth. However, only discontinuous graphene domains were produced, which will limit its applications.

Fig. 3 is the corresponding Raman spectra of the as-grown samples shown in Fig. 2. The D peak, G peak, and 2D peak, centered at around 1370,1580 , and $2700 \mathrm{~cm}^{-1}$ respectively, are the predominant features in each Raman spectrum. ${ }^{49}$ The 2D peak is a second-order two-phonon process related to a phonon near the $K$ point in graphene, corresponds to the dispersive nature, and strongly depends on any perturbation to the electronic and/or phonon structure of graphene, therefore the 2D peak is regarded as the signature of graphene to differentiate itself from other $\mathrm{sp}^{2}$ nanocarbons. ${ }^{50}$ The G peak is caused by the stretching of the $\mathrm{C}-\mathrm{C}$ bond in graphitic materials and is common in all $\mathrm{sp}^{2}$ carbon system. The $\mathrm{D}$ peak is caused by the disorder in the $\mathrm{sp}^{2}$ hybridized carbon atoms, and can be observed where symmetry is broken by edges or in samples with 

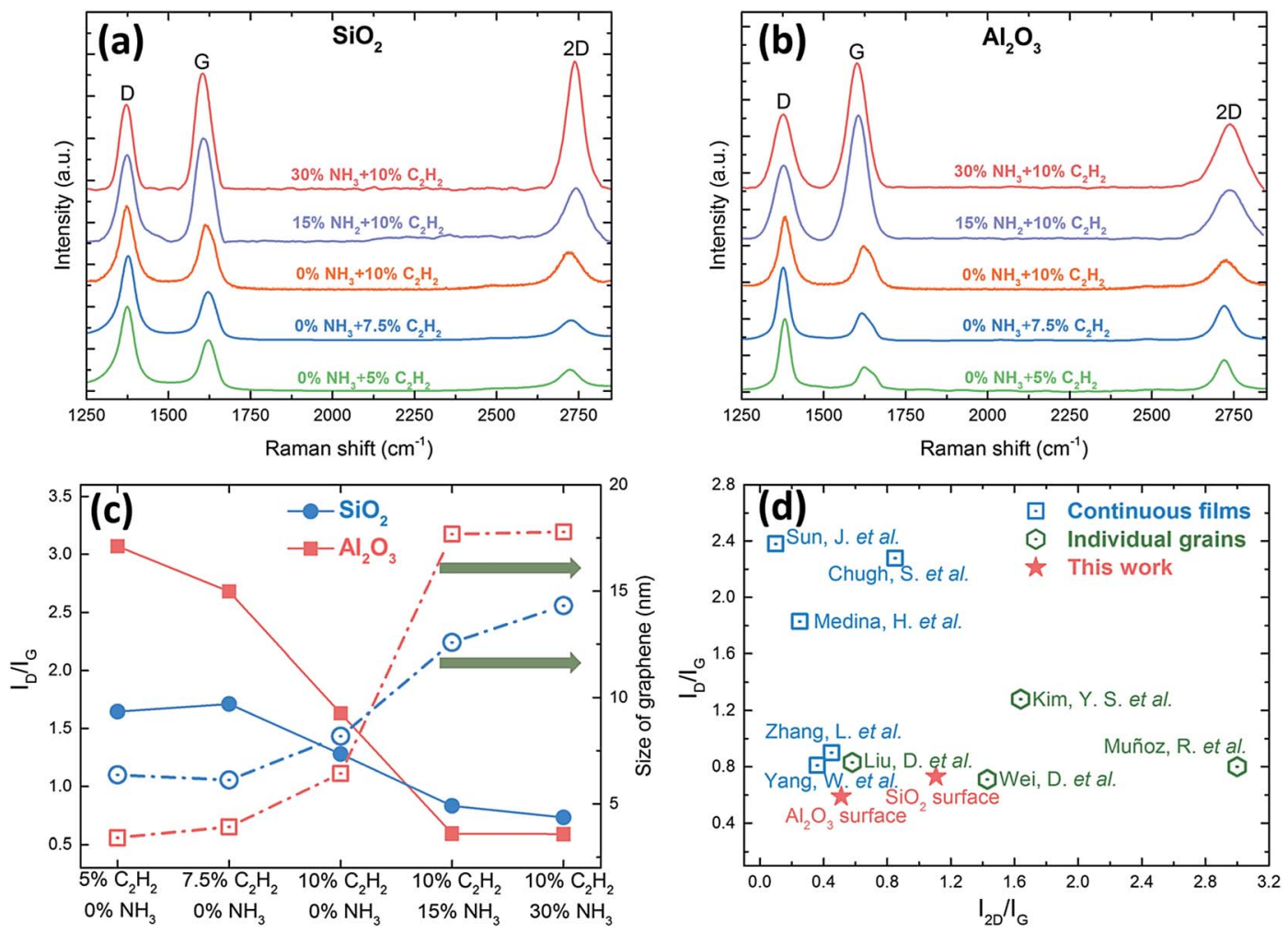

Fig. 3 (a, b) Corresponding Raman spectra of the as-grown samples shown in Fig. 2, and (c) the intensity ratios ( $I_{D} / I_{G}$, solid symbols and lines) and the sizes of graphene (open symbols and dash dot lines) of the as-grown graphene films under different conditions for three-hour synthesis at $750{ }^{\circ} \mathrm{C}$. (d) A summary of the intensity ratios of $I_{D} / I_{G}$ and $I_{2 D} / I_{G}$ of synthesizing graphene on insulators by PECVD method. Blue square: continuous films (Sun, J. et al., ${ }^{32}$ Chugh, S. et al., ${ }^{31}$ Medina, H. et al., ${ }^{35}$ Zhang, L. et al., ${ }^{38}$ and Yang, W. et al. ${ }^{36}$ ); green hexagon: individual grains (Kim, Y. S. et al., ${ }^{33}$ Liu, D. et al., ${ }^{30}$ Muñoz, R. et al., ${ }^{27}$ and Wei, D. et al. $\left.{ }^{28}\right)$; red star: this work.

a high density of defects. In order to compare the intensities of G peaks and 2D peaks among different samples, all the D peaks in our Raman spectra were normalized.

The intensity ratio of D peak to $\mathrm{G}$ peak $\left(I_{\mathrm{D}} / I_{\mathrm{G}}\right)$ can provide important information of the density of defects and the crystallite size of graphene. ${ }^{51}$ When evaluating these two methods of reducing 3D nano-walls, the method of introducing $\mathrm{NH}_{3}$ outweighs the method of decreasing the concentration of carbon source in reducing the density of defects and enlarging the crystallite size of graphene. Graphene grown on both $\mathrm{SiO}_{2}$ and $\mathrm{Al}_{2} \mathrm{O}_{3}$ substrates using $\mathrm{C}_{2} \mathrm{H}_{2} / \mathrm{H}_{2}$ plasma have a common feature that a relatively high density of defects caused by the high fraction of open edges of small crystallite sizes ${ }^{51}$ (Fig. 3a and b). By introducing $\mathrm{NH}_{3}, I_{\mathrm{D}} / I_{\mathrm{G}}$ on both $\mathrm{SiO}_{2}$ and $\mathrm{Al}_{2} \mathrm{O}_{3}$ substrates decreases greatly by $55.6 \%$ and $80.8 \%$ respectively (Fig. 3c). As $I_{\mathrm{D}} / I_{\mathrm{G}}$ is inversely proportional to the grain size $\left(L_{\mathrm{a}}\right)$ for $L_{\mathrm{a}}$ above $2 \mathrm{~nm}$, this can be used to study the level of disorder and assess the graphene quality. It can be also used to estimate the domain sizes (or crystal sizes) using Tuinstra and Koenig relation:

$$
L_{\mathrm{a}}(\mathrm{nm})=C\left(\lambda_{\mathrm{l}}\right)\left(I_{\mathrm{D}} / I_{\mathrm{G}}\right)^{-1}
$$

where $\lambda_{1}$ is the excitation laser wavelength, $C(457 \mathrm{~nm})$ $\sim 10.47 \mathrm{~nm} .{ }^{52,53}$ Fig. $3 \mathrm{c}$ also demonstrates the effect of reactant gases on $L_{\mathrm{a}}$. It can be seen, $L_{\mathrm{a}}$ increases dramatically from
$8.18 \mathrm{~nm}$ to $14.3 \mathrm{~nm}$ for graphene films grown on $\mathrm{SiO}_{2}$ substrates and from $6.42 \mathrm{~nm}$ to $17.8 \mathrm{~nm}$ for $\mathrm{Al}_{2} \mathrm{O}_{3}$ substrates when increasing the $\mathrm{NH}_{3}$ concentration from 0 to $30 \%$.

The high sensitivity to the specific $\mathrm{sp}^{2}$ nanocarbons makes the 2D Raman peak very useful in distinguishing graphene with different layers. ${ }^{54}$ For metal-catalyzed CVD graphene, the intensity ratio of $2 \mathrm{D}$ peak to $\mathrm{G}$ peak $\left(I_{2 \mathrm{D}} / I_{\mathrm{G}}\right) \approx 2$ and a single Lorentzian 2D peak with a full width at half maximum (FWHM) of $30 \mathrm{~cm}^{-1}$ indicate monolayer graphene, the feature of $1<I_{2 \mathrm{D}} /$ $I_{\mathrm{G}}<2$ with the $2 \mathrm{D}$ peak being fitted to four Lorentzian peaks is for bilayer graphene, and the feature of $I_{2 \mathrm{D}} / I_{\mathrm{G}}<1$ with the $2 \mathrm{D}$ peak being fitted to two Lorentzian peaks suggests multilayer graphene..$^{3,455}$ However, for metal-catalyst-free CVD graphene, $I_{2 \mathrm{D}} / I_{\mathrm{G}}$ for monolayer graphene is lower (around 1.2-1.5) and the FWHM of 2D peak is broader (around $60 \mathrm{~cm}^{-1}$ ) due to the nonnegligible $\mathrm{D}$ peak resulting in the breakage of the hexagonal symmetry in graphene. ${ }^{23,28,56}$ Among all the samples, the graphene grown on $\mathrm{SiO}_{2}$ substrate under $30 \% \mathrm{NH}_{3}$ shows that $I_{2 \mathrm{D}} /$ $I_{\mathrm{G}} \sim 1.11$ and the FWHM of $2 \mathrm{D}$ peak $\sim 57.1 \mathrm{~cm}^{-1}$, which implies monolayer graphene has been produced, and it further confirms the layer-by-layer structures observed by SEM in Fig. 2e. As for $\mathrm{Al}_{2} \mathrm{O}_{3}$, when increasing the $\mathrm{NH}_{3}$ concentration from $15 \%$ to $30 \%, I_{2 \mathrm{D}} / I_{\mathrm{G}}$ increases from 0.39 to 0.51 , which suggests that the as-grown graphene is multilayer, but its layer number reduces with the increase of $\mathrm{NH}_{3}$. Therefore, owing to the presence of $\mathrm{NH}_{3}$, and the growth mode turns from vertical 
graphene nano-walls to layer-by-layer films, and we can conclude that $30 \% \mathrm{NH}_{3}$ is the optical condition in our system to synthesize high-quality graphene with a lower density of defects, larger crystal sizes, and fewer layers for both substrates. Fig. 3d presents the summery of the intensity ratios $\left(I_{\mathrm{D}} / I_{\mathrm{G}}\right.$ and $\left.I_{2 \mathrm{D}} / I_{\mathrm{G}}\right)$ of graphene synthesized on insulators by PECVD method below $900{ }^{\circ} \mathrm{C}$. Compared to other published works, we have achieved the growth of uniform and continuous graphene films with the lowest $I_{\mathrm{D}} / I_{\mathrm{G}}$ using $\mathrm{C}_{2} \mathrm{H}_{2} /\left(\mathrm{H}_{2}+\mathrm{NH}_{3}\right)$ plasma, and $\mathrm{Al}_{2} \mathrm{O}_{3}$ demonstrates itself as a more competitive and suitable substrate for producing low-defect, large-area, and uniform graphene in comparison with $\mathrm{SiO}_{2}$.

To determine the electrical properties of the synthesized graphene, we fabricated back-gate graphene FETs directly using the as-grown samples without any post-transfer process. By using electron-beam lithography, oxygen plasma etching, metal deposition (5 $\mathrm{nm} \mathrm{Cr} / 50 \mathrm{~nm} \mathrm{Au}$ ), and lift-off technology, numbers of graphene FETs can be fabricated each time other than a single graphene domain device reported in previous work. ${ }^{28-30}$ The optical microscopy image of a typical graphene FET and its schematic structure are shown as the insets in Fig. 4a. Electrical characteristics were measured at room temperature in Keithley probe station. Fig. 4a shows the typical $I_{\mathrm{DS}}-V_{\mathrm{DS}}$ output curves of graphene devices fabricated from the sample of graphene prepared under $30 \% \mathrm{NH}_{3}$ (Fig. $2 \mathrm{j}$ ) at various gate voltages (from $-40 \mathrm{~V}$ to $40 \mathrm{~V}$ with a step of $20 \mathrm{~V}$ ). The symmetrical linear behavior implies an ohmic contact between electrodes and graphene channel. The contact resistances are in the range of 3.8-6.6 k $\Omega \square^{-1}$ measured by four-probe resistivity method. Fig. 4b gives the corresponding transfer curves (solid symbols) of typical five graphene FETs. For comparison, Fig. 4b also plots the transfer curve (open cycles) of a FET prepared under only $\mathrm{H}_{2}$ and $\mathrm{C}_{2} \mathrm{H}_{2}$. It can be seen that the FETs of graphene grown under $30 \% \mathrm{NH}_{3}$ show an ambipolar transfer characteristic with the Dirac point at negative gate voltages $(-20$ to $-30 \mathrm{~V})$. On the contrary, our FETs fabricated from graphene samples grown under $\mathrm{C}_{2} \mathrm{H}_{2} / \mathrm{H}_{2}$ plasma do not show such an ambipolar transfer characteristic yet even though the gate voltage spans from -60 to $+60 \mathrm{~V}$. This indicates that the introduction of $\mathrm{NH}_{3}$ has an n-type doping effect on the as-grown graphene, while the graphene is normally p-type FET behavior without $\mathrm{NH}_{3}$. This is consistent with previous reports using $\mathrm{NH}_{3}$ in the growth. ${ }^{28,57}$ The average field-effect mobility was estimated to be around $16 \mathrm{~cm}^{2} \mathrm{~V}^{-1} \mathrm{~s}^{-1}$, and the mobility values were extracted from the slope of $I_{\mathrm{DS}}-V_{\mathrm{BG}}$ based on the constant capacitance model of parallel capacitors. ${ }^{58}$

The n-type doping of graphene can be also confirmed by Raman spectroscopy. Our Raman spectra in Fig. 3a and b show large downshifts of the $\mathrm{G}$ bands for samples prepared under different $\mathrm{NH}_{3}$ concentrations $\left(11.8-13.5 \mathrm{~cm}^{-1}\right.$ for $\mathrm{SiO}_{2}$ samples and 16.7-21.6 $\mathrm{cm}^{-1}$ for $\mathrm{Al}_{2} \mathrm{O}_{3}$ samples) compared with the sample without using $\mathrm{NH}_{3}$. This is in accordance with reported $\mathrm{N}$-doped graphene, ${ }^{28,59}$ but different from ref. 60. Study has demonstrated that substitution of $\mathrm{C}$ atoms with graphitic $\mathrm{N}$ is $\mathrm{n}$ type doping with a downshift in $\mathrm{G}$ band, while pyridinic and pyrrolic $\mathrm{N}$ is p-type doping with a upshift in $\mathrm{G}$ band. ${ }^{61}$ This

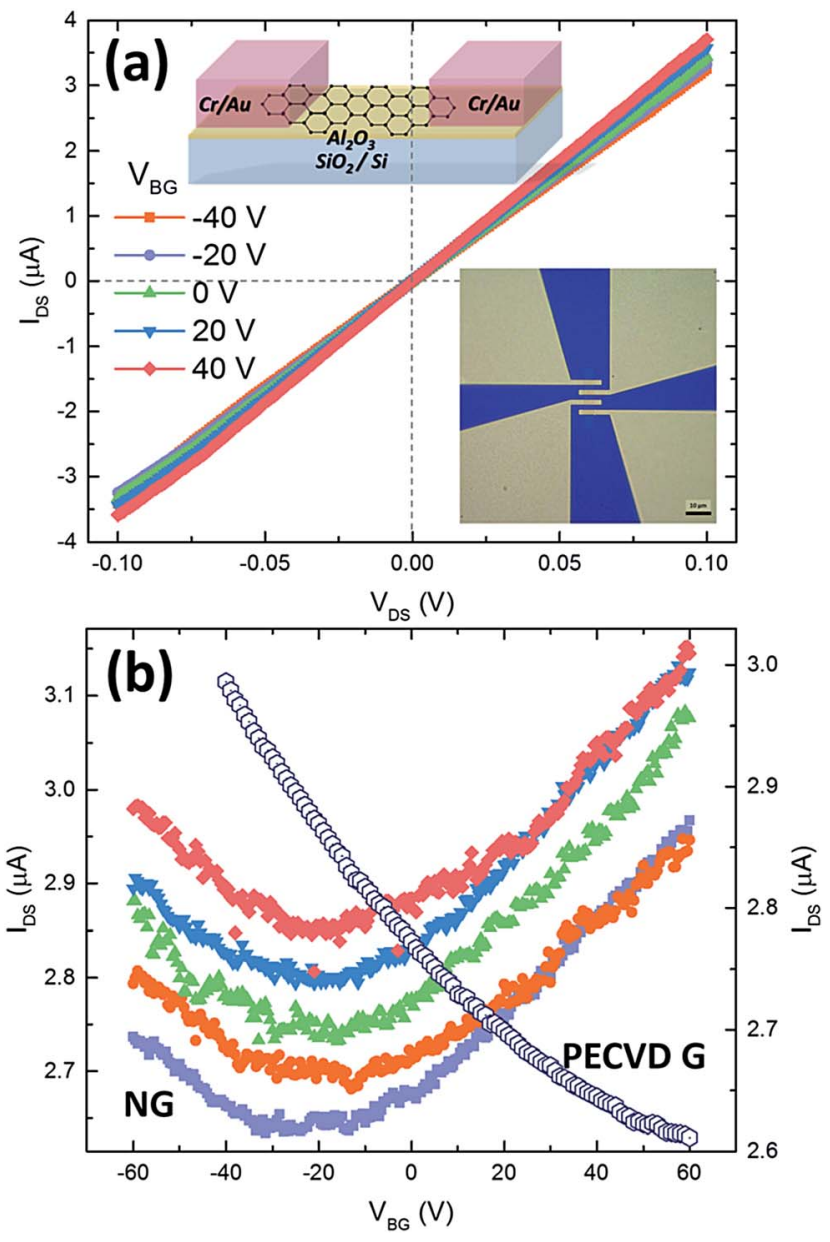

Fig. 4 Electrical properties of graphene synthesized directly on insulators. (a) Output characteristics of graphene FETs at different gate voltages. The inset is the schematic image of the device, and the optical microscopy image of the graphene device (the scale bar is 20 $\mu \mathrm{m})$. (b) Transfer characteristics of five graphene FETs of $\mathrm{N}$-doped graphene (NG, solid symbols) and a FET device of pristine graphene (PECVD G, open symbols) produced using only $\mathrm{H}_{2}$ and $\mathrm{C}_{2} \mathrm{H}_{2}\left(V_{D S}\right.$ at $100 \mathrm{mV})$.

means that our as-grown graphene is substitutionally doped by nitrogen atoms.

Besides the effect of $\mathrm{NH}_{3}$ concentration on the growth, the SEM images also indicate insulators have an effect on the surface morphologies of graphene. Under the same $\mathrm{NH}_{3}$ concentration and temperature, $\mathrm{Al}_{2} \mathrm{O}_{3}$ substrate favors a more effective nucleation stage and a faster growth stage compared with $\mathrm{SiO}_{2}$, resulting in either a higher density of 3D graphene nano-walls (Fig. 2c and h) or a better coverage on the substrate (Fig. 2e and j). The reason seems to be the smaller activation barrier of $\mathrm{Al}_{2} \mathrm{O}_{3}$ in the graphene growth, and such a low energy barrier ensures the dissociative adsorption of $\mathrm{C}_{2} \mathrm{H}_{2}$ to carbon adatom could happen at low temperature.

To further confirm that, a controlled experiment was conducted on $\mathrm{Al}_{2} \mathrm{O}_{3}$ substrates under the same growth condition (40 sccm $\mathrm{C}_{2} \mathrm{H}_{2}, 120 \mathrm{sccm} \mathrm{NH}_{3}$, and $240 \mathrm{sccm} \mathrm{H}_{2}$ ) by only decreasing the growth temperature from $750{ }^{\circ} \mathrm{C}$ to $650{ }^{\circ} \mathrm{C}$. At 

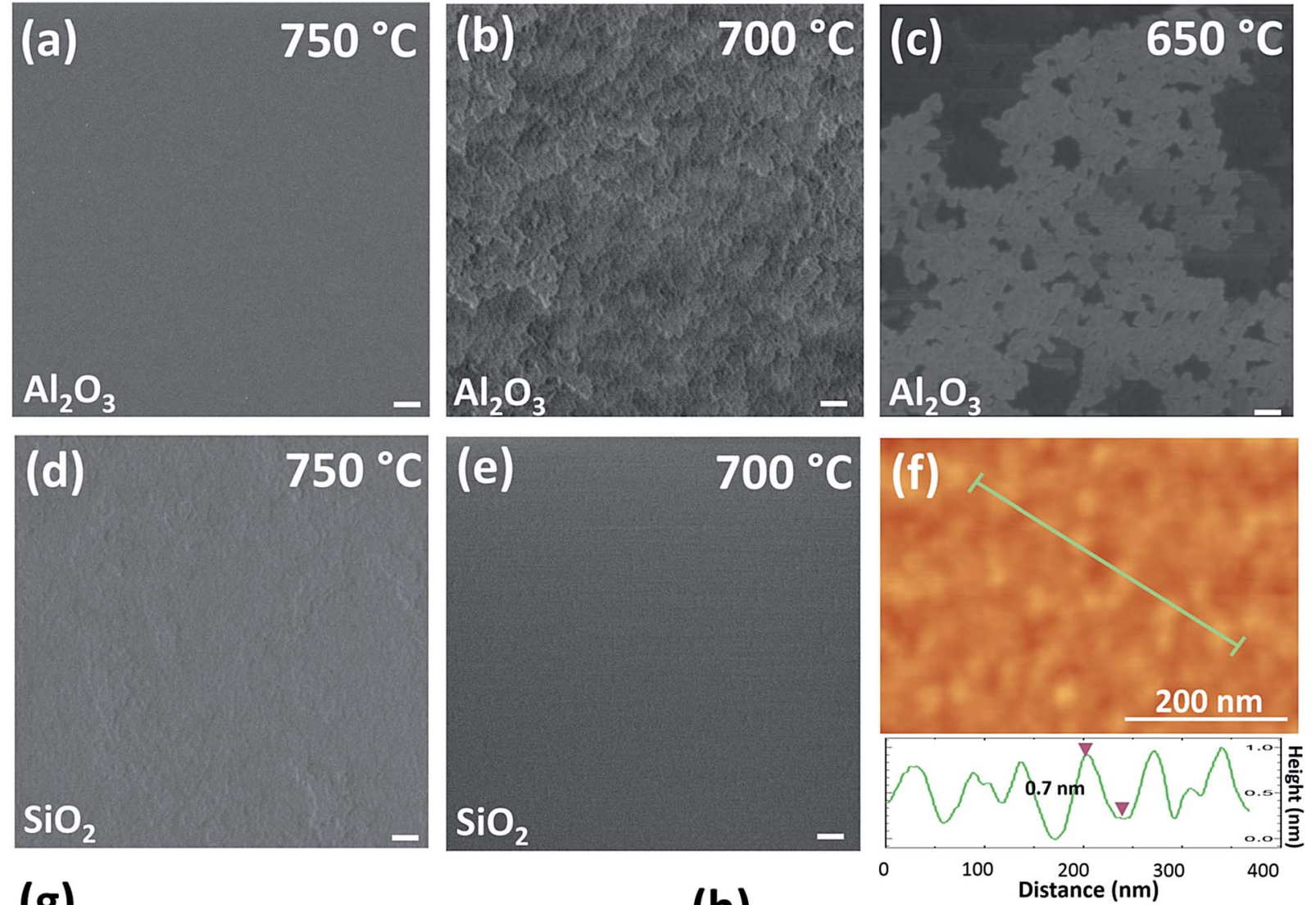

(g)

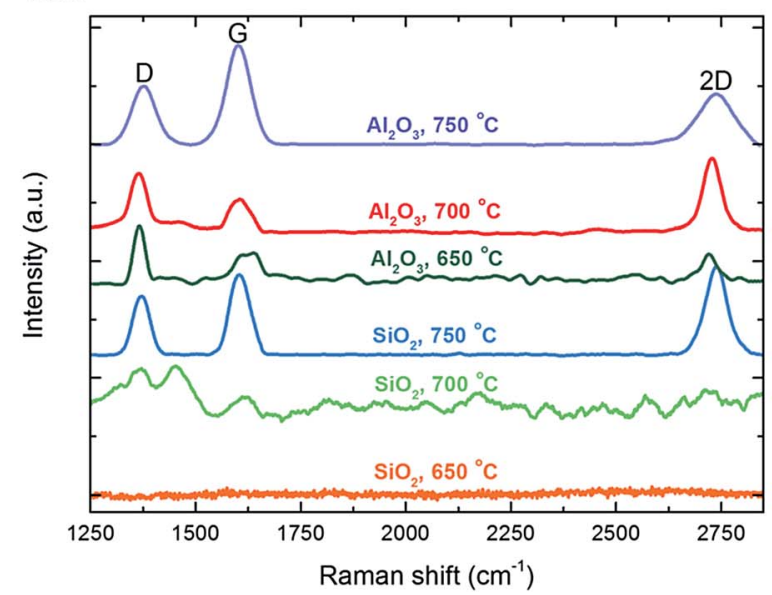

(h)

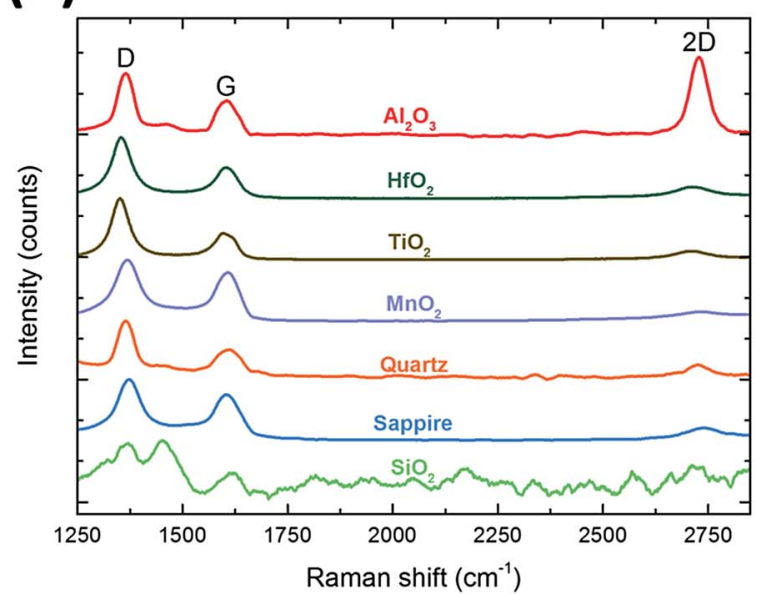

Fig. 5 Comparison of the growth under different temperatures with $30 \% \mathrm{NH}_{3}$ on $\mathrm{Al}_{2} \mathrm{O}_{3}$ substrates for 3 hours. SEM images of graphene grown at a temperature range of $750{ }^{\circ} \mathrm{C}$ to $650^{\circ} \mathrm{C}$ on $\mathrm{Al}_{2} \mathrm{O}_{3}\left(\mathrm{a}-\mathrm{C}\right.$ ), and $750{ }^{\circ} \mathrm{C}$ to $700{ }^{\circ} \mathrm{C}$ on $\mathrm{SiO}_{2}$ (d, e). The scale bars are $200 \mathrm{~nm}$. (f) $\mathrm{AFM}$ image of sample (b) and the thickness of its graphene flakes. (g) Corresponding Raman spectra of graphene samples grown on both substrates in the temperature range of $650-750{ }^{\circ} \mathrm{C}$. (h) Raman spectra of graphene sheets grown on different insulators with $30 \% \mathrm{NH}_{3}$ at $700{ }^{\circ} \mathrm{C}$ for 3 hours.

$750{ }^{\circ} \mathrm{C}$, a uniform and continuous graphene film is produced (Fig. 5a), and by decreasing the growth temperature to $700{ }^{\circ} \mathrm{C}$, graphene flakes are generated on the whole $\mathrm{Al}_{2} \mathrm{O}_{3}$ substrate (Fig. 5b). The Raman spectrum of sample (b) shown in Fig. $5 \mathrm{~g}$ presents a high level of defects $\left(I_{\mathrm{D}} / I_{\mathrm{G}} \sim 1.8\right)$ due to the disorder and asymmetry of graphene caused by a large amount of domain boundaries and defects inside the nanographene. Although the density of defects is high, a sharp $2 \mathrm{D}$ peak $\left(I_{2 \mathrm{D}} / I_{\mathrm{G}}\right.$ $\sim 2.27$ with the FWHM of $50.3 \mathrm{~cm}^{-1}$ ) and the thickness of
$0.7 \mathrm{~nm}$ measured by AFM (Fig. 5f) correspond to monolayer graphene. While at $750{ }^{\circ} \mathrm{C}, I_{2 \mathrm{D}} / I_{\mathrm{G}}$ decreases to 0.51 and the $2 \mathrm{D}$ peak becomes broader, implying that bilayer or multilayer graphene prefers a higher temperature. By decreasing the temperature, the crystal size of graphene decreases with the maximum value of $17.8 \mathrm{~nm}$ obtained at $750{ }^{\circ} \mathrm{C}$, implying that high temperature is beneficial to enlarge the size of graphene. When further decreasing the temperature into $650^{\circ} \mathrm{C}$, the whole substrate is partly covered with graphene flakes with a very high 
density of defects, which indicates the temperature of $650{ }^{\circ} \mathrm{C}$ is not able to provide enough energy for the growth (Fig. 5c and g). Therefore, on $\mathrm{Al}_{2} \mathrm{O}_{3}$ substrates, monolayer graphene growth favors a lower temperature of $700{ }^{\circ} \mathrm{C}$, while bilayer or multilayer graphene prefers a higher temperature of $750{ }^{\circ} \mathrm{C}$, which can promote a uniform coverage of the whole substrate, alleviate defects and disorders, and enlarge the crystal size at the same time. More importantly, the morphology of graphene grown on $\mathrm{Al}_{2} \mathrm{O}_{3}$ at $700{ }^{\circ} \mathrm{C}$ has similar layer-by-layer structures as that grown on $\mathrm{SiO}_{2}$ at $750{ }^{\circ} \mathrm{C}$ (Fig. 5d), while no graphene can be grown on $\mathrm{SiO}_{2}$ substrates at a temperature below $700{ }^{\circ} \mathrm{C}$ (Fig. 5e), as confirmed by Raman spectra of $\mathrm{SiO}_{2}$ in Fig. $5 \mathrm{~g}$. Therefore, the growth-temperature windows of these two insulators are different, which implies insulators might have different catalytic effect on the graphene growth. Part et al. carried out Density Functional Theory (DFT) calculations of activation barriers among $\mathrm{Cu}, \mathrm{Ni}$, and $\mathrm{Al}_{2} \mathrm{O}_{3}$ for graphene growth. ${ }^{62}$ Among these activation barriers, the supply of $\mathrm{C}$ adatoms governed by $E_{\mathrm{ad}}$ and the enlargement of the graphene nuclei governed by $E_{\text {att }}$ determine the lowest possible growth temperature. ${ }^{62}$ From their theoretical calculations, both $E_{\mathrm{ad}}$ and $E_{\text {att }}$ of $\mathrm{Al}_{2} \mathrm{O}_{3}$ are much lower than those of $\mathrm{Cu}$ while similar to the values of $\mathrm{Ni}$. This indicates the graphene formation on $\mathrm{Al}_{2} \mathrm{O}_{3}$ could potentially be achieved at a temperature comparable to nearly the room-temperature synthesis of graphene on $\mathrm{Ni}^{63}$ Besides $\mathrm{Al}_{2} \mathrm{O}_{3}$ and $\mathrm{SiO}_{2}$, other insulators including $\mathrm{HfO}_{2}, \mathrm{TiO}_{2}$, $\mathrm{MnO}_{2}$, quartz, and sapphire have also been used as substrates under the same condition. As their Raman spectra with low 2D peaks and high $\mathrm{D}$ peaks show in Fig. $5 \mathrm{~h}$, they are not as suitable as $\mathrm{Al}_{2} \mathrm{O}_{3}$ to produce monolayer and low-defect graphene at $700{ }^{\circ} \mathrm{C}$. Therefore, the similarity and difference in the morphology of graphene on various insulators suggest that insulators might have different growth windows due to their different activation barriers, and our experiments demonstrate that $\mathrm{Al}_{2} \mathrm{O}_{3}$ substrates have the lowest activation barrier among others, which enables it to produce the similar structures at relatively low temperature. Further theoretical studies via DFT simulations to calculate the activation barriers of various insulators are still needed in the future, which will be beneficial to understand the potential of different insulating substrates for the low-temperature growth of graphene.

Why can the growth mode of graphene be changed from 3D nano-walls to layer-to-layer films, and why is it n-type doped? Previous studies have shown that $\mathrm{NH}_{3}$ is a much stronger etchant than $\mathrm{H}_{2}$ to produce atomic hydrogen under plasma conditions, which can selectively etch away the amorphous carbon on graphene and remove defects generated at the graphene edges, thus keeping the edges atomically smooth and active during the graphene crystal growth. ${ }^{28,44,57}$ However, this could not well answer the questions. In fact, the reactions in the plasma is very complicated, which can hardly be explained by a few simple chemical reaction equations. It depends not only on the plasma type (for example, DC plasma, RF inductively coupled plasma (ICP), microwave plasma, etc.) and the plasma power, but also on the plasma gases and pressure. Mao et al. intensively investigated the plasma chemistry of different binary gas mixtures $\left(\mathrm{CH}_{4} / \mathrm{H}_{2}\right.$, $\mathrm{CH}_{4} / \mathrm{NH}_{3}, \mathrm{C}_{2} \mathrm{H}_{2} / \mathrm{H}_{2}$ and $\mathrm{C}_{2} \mathrm{H}_{2} / \mathrm{NH}_{3}$ ) for the synthesis of carbon nanotubes/nanofibers by ICP enhanced CVD. ${ }^{64}$ It is found that tens of species will be formed in the plasma. Although the atomic hydrogen produced by $\mathrm{CH}_{4} / \mathrm{NH}_{3}$ plasma is significantly higher than that by $\mathrm{CH}_{4} / \mathrm{H}_{2}$ plasma at 1 torr or high pressure, the atomic hydrogen produced by $\mathrm{C}_{2} \mathrm{H}_{2} / \mathrm{NH}_{3}$ plasma is similar to that by $\mathrm{C}_{2} \mathrm{H}_{2} / \mathrm{H}_{2}$ plasma. The most fundamental thing is that long-chain hydrocarbons such as $\mathrm{C}_{2 n} \mathrm{H}_{2}$ and $\mathrm{C}_{2 n} \mathrm{H}_{6}$ ( $n$ up to 6) are formed and become important in the $\mathrm{C}_{2} \mathrm{H}_{2} / \mathrm{H}_{2}$ plasma. On the contrary, the formation of these long-chain hydrocarbon is less important in the $\mathrm{C}_{2} \mathrm{H}_{2} / \mathrm{NH}_{3}$ plasma. We speculate that some long-chain hydrocarbons under $\mathrm{C}_{2} \mathrm{H}_{2} / \mathrm{H}_{2}$ plasma can deposit randomly onto the substrate and develop into 3D nano-walls. By introducing higher concentration of $\mathrm{NH}_{3}$ the formation of long chain hydrocarbon is greatly suppressed, therefore the growth of $3 \mathrm{D}$ nano-walls is eliminated. We also believe the atomic hydrogen plays an important role in our system. This is because $\mathrm{NH}_{3}$ can be thermally decomposed to enough atomic hydrogen on the surface of substrate at $650-750{ }^{\circ} \mathrm{C}^{65}$ While the thermal decomposition of $\mathrm{H}_{2}$ can be ignored due to its high stability. This explains why the quality of graphene is improved by introducing $\mathrm{NH}_{3}$. On the other hand, active $\mathrm{HCN}$ species can be also produced in the plasma, which can attach to the edge of graphene and form the substitutionally $\mathrm{N}$-doped graphene. This results in amounts of graphitic $\mathrm{N},{ }^{57}$ leading to a Dirac point shift at a negative gate voltage and the downshifts of the $\mathrm{G}$ peaks in Raman spectra.

\section{Conclusions}

In summary, we have demonstrated a microwave PECVD method of synthesizing graphene on both $\mathrm{SiO}_{2}$ and $\mathrm{Al}_{2} \mathrm{O}_{3}$ substrates without using any metal catalysts. By introducing $\mathrm{NH}_{3}$ to suppress the formation of long-chain hydrocarbon in the plasma and to enhance the etching effect, we have obtained uniform and continuous graphene films with the lowest density of defects among all the PECVD growth of graphene. Further investigation of the effect of insulating substrates on the growth shows that the growth-temperature window and catalytic effect are different for each insulator owing to the different activation barrier. $\mathrm{Al}_{2} \mathrm{O}_{3}$ seems to own a lower activation barrier, which makes it a promising candidate as the substrate for the metalcatalyst-free growth of graphene at low temperature. This direct assembly of graphene on high- $\mathrm{Al}_{2} \mathrm{O}_{3}$ thin films can be flexibly incorporated into electronic and optoelectronic devices without any post-growth transfer process. More improvements are still needed in largely increasing the grain size, further reducing the growth temperature, and better controlling the number of layers. We believe our work provides an important step towards large-scale, low-cost and high-quality synthesis of graphene on arbitrary substrates.

\section{Acknowledgements}

We thank EPSRC grant EP/P005152/1 and the Cambridge Commonwealth, European and International Trust for funding. S. Z. would like to acknowledge Prof. Stephan Hofmann and Dr Yuzheng Guo for helpful discussions. 


\section{References}

1 K. S. Novoselov, A. K. Geim, S. V. Morozov, D. Jiang, Y. Zhang, S. V. Dubonos, I. V. Grigorieva and A. A. Firsov, Science, 2004, 306, 666-669.

2 K. S. Novoselov, V. I. Fal'ko, L. Colombo, P. R. Gellert, M. G. Schwab and K. Kim, Nature, 2012, 490, 192-200.

3 K. S. Kim, Y. Zhao, H. Jang, S. Y. Lee, J. M. Kim, K. S. Kim, J.-H. Ahn, P. Kim, J.-Y. Choi and B. H. Hong, Nature, 2009, 457, 706-710.

4 X. Li, W. Cai, J. An, S. Kim, J. Nah, D. Yang, R. Piner, A. Velamakanni, I. Jung, E. Tutuc, S. K. Banerjee, L. Colombo and R. S. Ruoff, Science, 2009, 324, 1312-1314.

5 Q. Yu, J. Lian, S. Siriponglert, H. Li, Y. P. Chen and S. S. Pei, Appl. Phys. Lett., 2008, 93, 113103.

6 P. R. Kidambi, C. Ducati, B. Dlubak, D. Gardiner, R. S. Weatherup, M. B. Martin, P. Seneor, H. Coles and S. Hofmann, J. Phys. Chem. C, 2012, 116, 22492-22501.

7 R. S. Weatherup, B. C. Bayer, R. Blume, C. Ducati, C. Baehtz, R. Schlögl and S. Hofmann, Nano Lett., 2011, 11, 4154-4160.

8 G. Zhong, X. Wu, L. D'Arsie, K. B. K. Teo, N. L. Rupesinghe, A. Jouvray and J. Robertson, Appl. Phys. Lett., 2016, 109, 193103.

9 S. Bae, H. Kim, Y. Lee, X. Xu, J.-S. Park, Y. Zheng, J. Balakrishnan, T. Lei, H. R. Kim, Y. Il Song, Y.-J. Kim, K. S. Kim, B. Ozyilmaz, J.-H. Ahn, B. H. Hong and S. Iijima, Nat. Nanotechnol., 2010, 5, 574-578.

10 J. Kang, D. Shin, S. Bae and B. H. Hong, Nanoscale, 2012, 4, 5527.

11 S. R. Na, J. W. Suk, L. Tao, D. Akinwande, R. S. Ruoff, R. Huang and K. M. Liechti, ACS Nano, 2015, 9, 1325-1335.

12 W. Zhang, P. Wu, Z. Li and J. Yang, J. Phys. Chem. C, 2011, 115, 17782-17787.

13 S. A. Steiner, T. F. Baumann, B. C. Bayer, R. Blume, M. A. Worsley, W. J. MoberlyChan, E. L. Shaw, R. Schlögl, A. J. Hart, S. Hofmann and B. L. Wardle, J. Am. Chem. Soc., 2009, 131, 12144-12154.

14 A. Kudo, S. A. Steiner, B. C. Bayer, P. R. Kidambi, S. Hofmann, M. S. Strano and B. L. Wardle, J. Am. Chem. Soc., 2014, 136, 17808-17817.

15 M. H. Rümmeli, A. Bachmatiuk, A. Scott, F. Börrnert, J. H. Warner, V. Hoffman, J. H. Lin, G. Cuniberti and B. Büchner, ACS Nano, 2010, 4, 4206-4210.

16 A. Scott, A. Dianat, F. Börrnert, A. Bachmatiuk, S. Zhang, J. H. Warner, E. Borowiak-Paleń, M. Knupfer, B. Büchner, G. Cuniberti and M. H. Rümmeli, Appl. Phys. Lett., 2011, 98, 73110.

17 P.-Y. Teng, C.-C. Lu, K. Akiyama-Hasegawa, Y.-C. Lin, C.-H. Yeh, K. Suenaga and P.-W. Chiu, Nano Lett., 2012, 12, 1379-1384.

18 J. Sun, Y. Zhang and Z. Liu, ChemNanoMat, 2016, 2, 9-18.

19 D. Geng, H. Wang and G. Yu, Adv. Mater., 2015, 27, 28212837.

20 J. Chen, Y. Wen, Y. Guo, B. Wu, L. Huang, Y. Xue, D. Geng, D. Wang, G. Yu and Y. Liu, J. Am. Chem. Soc., 2011, 133, 17548-17551.
21 J. Chen, Y. Guo, L. Jiang, Z. Xu, L. Huang, Y. Xue, D. Geng, B. Wu, W. Hu, G. Yu and Y. Liu, Adv. Mater., 2014, 26, 1348-1353.

22 Q. Liu, Y. Gong, T. Wang, W.-L. Chan and J. Wu, Carbon, 2016, 96, 203-211.

23 M. A. Fanton, J. A. Robinson, C. Puls, Y. Liu, M. J. Hollander, B. E. Weiland, M. Labella, K. Trumbull, R. Kasarda, C. Howsare, J. Stitt and D. W. Snyder, ACS Nano, 2011, 5, 8062-8069.

24 J. Hwang, M. Kim, D. Campbell, H. A. Alsalman, J. Y. Kwak, S. Shivaraman, A. R. Woll, A. K. Singh, R. G. Hennig, S. Gorantla, M. H. Rümmeli and M. G. Spencer, ACS Nano, 2013, 7, 385-395.

25 J. Kim, M. Ishihara, Y. Koga, K. Tsugawa, M. Hasegawa and S. Iijima, Appl. Phys. Lett., 2011, 98, 91502.

26 X. Chen, B. Wu and Y. Liu, Chem. Soc. Rev., 2016, 45, 20572074.

27 R. Muñoz, C. Munuera, J. I. Martínez, J. Azpeitia, C. GómezAleixandre and M. García-Hernández, 2D Mater., 2017, 4, 15009.

28 D. Wei, L. Peng, M. Li, H. Mao, T. Niu, C. Han, C. Wei, W. Chen, A. Thye and S. Wee, ACS Nano, 2015, 1, 1-15.

29 D. Wei, Y. Lu, C. Han, T. Niu, W. Chen and A. T. S. Wee, Angew. Chem., Int. Ed., 2013, 52, 14121-14126.

30 D. Liu, W. Yang, L. Zhang, J. Zhang, J. Meng, R. Yang, G. Zhang and D. Shi, Carbon, 2014, 72, 387-392.

31 S. Chugh, R. Mehta, N. Lu, F. D. Dios, M. J. Kim and Z. Chen, Carbon, 2015, 93, 393-399.

32 J. Sun, M. E. Schmidt, M. Muruganathan, H. M. H. Chong and H. Mizuta, Nanoscale, 2016, 8, 6659-6665.

33 Y. S. Kim, K. Joo, S.-K. Jerng, J. H. Lee, E. Yoon and S.-H. Chun, Nanoscale, 2014, 6, 10100-10105.

34 C. Yang, H. Bi, D. Wan, F. Huang, X. Xie and M. Jiang, J. Mater. Chem. A, 2013, 770-775.

35 H. Medina, Y.-C. Lin, C. Jin, C.-C. Lu, C.-H. Yeh, K.-P. Huang, K. Suenaga, J. Robertson and P.-W. Chiu, Adv. Funct. Mater., 2012, 22, 2123-2128.

36 W. Yang, C. He, L. Zhang, Y. Wang, Z. Shi, M. Cheng, G. Xie, D. Wang, R. Yang, D. Shi and G. Zhang, Small, 2012, 8, 14291435.

37 A. Malesevic, R. Vitchev, K. Schouteden, A. Volodin, L. Zhang, G. Van Tendeloo, A. Vanhulsel and C. Van Haesendonck, Nanotechnology, 2008, 19, 305604.

38 L. Zhang, Z. Shi, Y. Wang, R. Yang, D. Shi and G. Zhang, Nano Res., 2010, 4, 315-321.

39 J. Sun, Y. Chen, X. Cai, B. Ma, Z. Chen, M. K. Priydarshi, K. Chen and T. Gao, Nano Res., 2015, 8, 3496-3504.

40 A. T. H. Chuang, J. Robertson, B. O. Boskovic and K. K. K. Koziol, Appl. Phys. Lett., 2007, 90, 123107.

41 Y. Zhang, V. W. Brar, C. Girit, A. Zettl and M. F. Crommie, Nat. Phys., 2009, 5, 722-726.

42 S. Kim, J. Nah, I. Jo, D. Shahrjerdi, L. Colombo, Z. Yao, E. Tutuc and S. K. Banerjee, Appl. Phys. Lett., 2009, 94, 62107.

43 B. Dlubak, P. R. Kidambi, R. S. Weatherup, S. Hofmann and J. Robertson, Appl. Phys. Lett., 2012, 100(17), 173113.

44 L. Zhang, M. Ni, D. Liu, D. Shi and G. Zhang, J. Phys. Chem. C, 2012, 116, 26929-26931. 
45 L. Xie, L. Jiao and H. Dai, J. Am. Chem. Soc., 2010, 132, 1475114753.

46 M. S. Bell, R. G. Lacerda, K. B. K. Teo, N. L. Rupesinghe, G. A. J. Amaratunga, W. I. Milne and M. Chhowalla, Appl. Phys. Lett., 2004, 85, 1137-1139.

47 M. S. Bell, K. B. K. Teo, R. G. Lacerda, W. I. Milne, D. B. Hash and M. Meyyappan, Pure Appl. Chem., 2006, 78, 1117-1125.

48 D. H. Lee, W. J. Lee and S. O. Kim, Nano Lett., 2009, 9, 14271432.

49 A. C. Ferrari, J. C. Meyer, V. Scardaci, C. Casiraghi, M. Lazzeri, F. Mauri, S. Piscanec, D. Jiang, K. S. Novoselov, S. Roth and a. K. Geim, Phys. Rev. Lett., 2006, 97, 187401.

50 M. S. Dresselhaus, A. Jorio, M. Hofmann, G. Dresselhaus and R. Saito, Nano Lett., 2010, 10, 751-758.

51 A. C. Ferrari, Solid State Commun., 2007, 143, 47-57.

52 A. C. Ferrari and J. Robertson, Phys. Rev. B: Condens. Matter Mater. Phys., 2000, 61, 14095-14107.

53 L. G. Caņado, K. Takai, T. Enoki, M. Endo, Y. a. Kim, H. Mizusaki, A. Jorio, L. N. Coelho, R. Magalhães-Paniago and M. a. Pimenta, Appl. Phys. Lett., 2006, 88, 12-14.

54 L. M. Malard, M. a. Pimenta, G. Dresselhaus and M. S. Dresselhaus, Phys. Rep., 2009, 473, 51-87.

55 D. Graf, F. Molitor, K. Ensslin, C. Stampfer, A. Jungen, C. Hierold and L. Wirtz, Nano Lett., 2007, 7, 238-242.
56 S. Xu, B. Man, S. Jiang, W. Yue, C. Yang, M. Liu, C. Chen and C. Zhang, Nanotechnology, 2014, 25, 165702.

57 D. Wei, Y. Liu, Y. Wang, H. Zhang, L. Huang and G. Yu, Nano Lett., 2009, 9, 1752-1758.

58 D. K. Schroder, Semiconductor Material and Device Characterization, John Wiley \& Sons, 2006.

59 L. Zhao, R. He, K. T. Rim, T. Schiros, K. S. Kim, H. Zhou, C. Gutierrez, S. P. Chockalingam, C. J. Arguello, L. Palova, D. Nordlund, M. S. Hybertsen, D. R. Reichman, T. F. Heinz, P. Kim, A. Pinczuk, G. W. Flynn and A. N. Pasupathy, Science, 2011, 333, 999-1003.

60 S. M. Shinde, E. Kano, G. Kalita, M. Takeguchi, A. Hashimoto and M. Tanemura, Carbon, 2016, 96, 448-453.

61 D. Deng, X. Pan, L. Yu, Y. Cui, Y. Jiang, J. Qi, W. X. Li, Q. Fu, X. Ma, Q. Xue, G. Sun and X. Bao, Chem. Mater., 2011, 23, 1188-1193.

62 J. Park, J. Lee, J.-H. Choi, D. K. Hwang and Y.-W. Song, Sci. Rep., 2015, 5, 11839.

63 J. Kwak, J. H. Chu, J.-K. Choi, S.-D. Park, H. Go, S. Y. Kim, K. Park, S.-D. Kim, Y.-W. Kim, E. Yoon, S. Kodambaka and S.-Y. Kwon, Nat. Commun., 2012, 3, 645.

64 M. Mao and A. Bogaerts, J. Phys. D: Appl. Phys., 2010, 43, 205201.

65 A. H. White and W. M. Melville, J. Am. Chem. Soc., 1904, 27, 373-386. 